\title{
Postoperative Pain Management in Enhanced Recovery Pathways
}

\author{
Christopher K Cheung \\ Janet O Adeola \\ Sascha S Beutler \\ Richard D Urman (1D) \\ Department of Anesthesiology, \\ Perioperative and Pain Medicine, Brigham \\ and Women's Hospital, Harvard Medical \\ School, Boston, MA, USA
}

\begin{abstract}
Postoperative pain is a common but often inadequately treated condition. Enhanced recovery pathways (ERPs) are increasingly being utilized to standardize perioperative care and improve outcomes. ERPs employ multimodal postoperative pain management strategies that minimize opioid use and promote recovery. While traditional opioid medications continue to play an important role in the treatment of postoperative pain, ERPs also rely on a wide range of non-opioid pharmacologic therapies as well as regional anesthesia techniques to manage pain in the postoperative setting. The evidence for the use of these interventions continues to evolve rapidly given the increasing focus on enhanced postoperative recovery. This article reviews the current evidence and knowledge gaps pertaining to commonly utilized modalities for postoperative pain management in ERPs.

Keywords: enhanced recovery after surgery, ERAS, multimodal analgesia, opioid-sparing analgesia, postsurgical pain, pain management
\end{abstract}

\section{Introduction}

Postoperative pain is a common but often inadequately treated condition, with $80 \%$ of surgical patients experiencing postoperative pain but less than $50 \%$ of these patients reporting sufficient pain control according to a US Institute of Medicine report. ${ }^{1}$ In addition, a national survey suggests that $39 \%$ of patients with postoperative pain experience severe to extreme levels of pain. ${ }^{2}$ The consequences of suboptimal postoperative pain control include elevated risk for morbidity and persistent postsurgical pain as well as increased length of hospital stay and healthcare costs. ${ }^{3}$ Pain management in the postoperative setting presents a challenge as the development and severity of pain after surgery is dependent on various patient and procedural factors. ${ }^{4-6}$ Furthermore, opioid medications, the traditional mainstay of postoperative pain treatment, are associated with significant short- and long-term adverse effects. ${ }^{7,8}$ Over the past two decades, structured perioperative programs known as enhanced recovery pathways (ERPs) have been developed in order to standardize care and improve outcomes. ${ }^{9}$ These pathways, which are often built around procedure-specific, evidence-based guidelines from organizations such as the Enhanced Recovery After Surgery (ERAS) Society, Procedure-Specific Postoperative Pain Management (PROSPECT) group, and the American Society for Enhanced Recovery (ASER), are increasingly considered standard of care for patients undergoing a variety of surgical procedures. ${ }^{10-12}$ With regard to postoperative pain management, ERPs apply a multimodal, opioid-sparing approach. ${ }^{13}$ In particular, non-opioid medications and regional anesthesia techniques are
Correspondence: Richard D Urman Department of Anesthesiology, Perioperative and Pain Medicine, Brigham and Women's Hospital, Harvard Medical School, 75 Francis Street, CWN LI, Boston, MA, 02115, USA

Tel + I 6177328210

Fax + I6I7264684I

Email rurman@bwh.harvard.edu 
commonly employed to minimize use of opioid medications. ${ }^{14}$ As strategies for postoperative pain treatment continue to evolve rapidly in the context of an increasing focus on enhanced postoperative recovery, ${ }^{15}$ we review the current evidence as well as knowledge gaps and controversies pertaining to commonly utilized postoperative pain management modalities in ERPs.

\section{Methods}

This article is a narrative review of the literature on the management of postoperative pain in the context of ERPs. The primary objective of this review is to provide an overview of salient pain management modalities employed by ERPs in the postoperative setting as well as the current evidence and recommendations for their use. We identified pertinent treatment modalities by reviewing current postoperative pain management guidelines published by the Enhanced Recovery After Surgery (ERAS) Society, Procedure-Specific Postoperative Pain Management (PROSPECT) group, and the American Society for Enhanced Recovery (ASER), including its Perioperative Quality Initiative (POQI). In addition, we reviewed articles obtained via searches of the PubMed database and Google Scholar for the following terms: "enhanced recovery pain management", "enhanced recovery analgesia", "multimodal analgesia", and "opioid-sparing analgesia". We only included treatment modalities employed in the postoperative setting and excluded preemptive analgesia and intraoperative management techniques. After identifying commonly utilized treatment modalities, we then reviewed articles pertaining to each individual treatment modality obtained by searching the PubMed database, Cochrane Library database, and Google Scholar using the term "postoperative pain" plus the name of the specific treatment modality (eg "acetaminophen", "epidural", etc.). We excluded studies performed solely in the pediatric population.

\section{Opioid Medications}

Opioid medications such as fentanyl, morphine, hydromorphone, oxycodone, and hydrocodone exert their analgesic action through the mu opioid receptor. Opioids are traditionally considered integral to postoperative pain management, but their use is associated with a number of adverse effects including urinary retention, ileus, nausea, vomiting, pruritus, respiratory depression, and central nervous system depression. ${ }^{7}$ These adverse effects are associated with increased mortality, length of stay, risk for readmission, and healthcare costs in surgical patients. ${ }^{16,17}$ Opioid use can also lead to tolerance and opioid-induced hyperalgesia, which may in turn contribute to the development of persistent postsurgical pain. ${ }^{18}$ Furthermore, opioid use in the postoperative setting is associated with increased risk of chronic opioid use, which is particularly concerning in the context of the current national opioid epidemic. ${ }^{19}$ Therefore, ERPs generally utilize opioid medications sparingly, only for moderate-to-severe pain not responsive to other treatments, and always in conjunction with nonopioid analgesic interventions (Table 1). The use of nonopioid analgesic modalities is especially important in patients with chronic pain who take opioids preoperatively as these patients are at increased risk for severe postoperative pain, poor postoperative pain control, and opioidrelated adverse effects in the postoperative setting. 5,6,20,21

Implementation of ERPs has been shown to significantly reduce inpatient opioid consumption after a wide range of surgical procedures. ${ }^{22-31}$ Zhao et al demonstrated a dose-response relationship between postoperative opioid consumption and opioid-related adverse effects. ${ }^{32}$ Accordingly, several studies suggest opioid-sparing strategies may be associated with lower rates of opioid-related adverse effects, including nausea, vomiting, sedation, urinary retention, and constipation. ${ }^{24,30-36}$ Reduced consumption of opioids does not appear to negatively impact patient-reported pain or satisfaction levels and, in some studies, is associated with improved patient-reported pain scores. ${ }^{25-31,34-38}$ The effect of opioid-sparing strategies during the acute postoperative period on chronic opioid use remains unclear, with some studies demonstrating a reduction of longer term opioid use while others showing no difference. ${ }^{30,38-43}$ Although opioid-sparing postoperative analgesic interventions have clear advantages with respect to reduced adverse effects and some studies even suggest that opioid medications may provide superior analgesia for acute pain compared to non-opioid therapies, the feasibility of opioid-free postoperative analgesia remains controversial and additional research in this area is needed. ${ }^{44-46}$

If opioids are required during the postoperative period, ERPs generally recommend that they be administered orally for patients who are tolerating oral intake. Shortacting rather than long-acting opioids should be used in patients who are not taking opioids chronically as shortacting opioids are more easily titratable and associated with a lower risk of unintentional overdose. ${ }^{47}$ In patients with renal failure, morphine and codeine are generally 
Table I Common Non-Opioid Modalities for Treatment of Postoperative Pain in Enhanced Recovery Pathways

\begin{tabular}{|c|c|c|}
\hline Modality & Advantages & Disadvantages \\
\hline Acetaminophen & $\begin{array}{l}\text { - Reduced opioid requirements } \\
\text { - Improved pain control } \\
\text { - Generally well-tolerated } \\
\text { - Synergistic analgesic effect when combined } \\
\text { with NSAIDs }\end{array}$ & $\begin{array}{l}\text { - Hepatotoxicity with higher doses } \\
\text { - Caution in patients with liver dysfunction }\end{array}$ \\
\hline $\begin{array}{l}\text { Nonsteroidal anti- } \\
\text { inflammatory drugs } \\
\text { (NSAIDs) }\end{array}$ & $\begin{array}{l}\text { - Reduced opioid requirements } \\
\text { - Improved pain control } \\
\text { - Synergistic analgesic effect when combined } \\
\text { with acetaminophen }\end{array}$ & $\begin{array}{l}\text { - Risk of gastrointestinal ulceration, bleeding, renal impairment, and } \\
\text { cardiovascular adverse events } \\
\text { - Possible association with bone nonunion after spinal fusion } \\
\text { - Possible association with anastomotic leak after colorectal surgery }\end{array}$ \\
\hline Gabapentinoids & $\begin{array}{l}\text { - Reduced opioid requirements } \\
\text { - Improved pain control }\end{array}$ & $\begin{array}{l}\text { - Benefits of questionable clinical significance } \\
\text { - Risk of sedation, visual disturbances, and respiratory depression } \\
\text { - Caution in patients with renal dysfunction } \\
\text { - Only available in oral formulations } \\
\text { - Optimal dosing regimen unclear }\end{array}$ \\
\hline Alpha-2 agonists & $\begin{array}{l}\text { - Reduced opioid requirements } \\
\text { - Improved pain control } \\
\text { - Can be used as adjuncts in regional } \\
\text { anesthetic techniques }\end{array}$ & $\begin{array}{l}\text { - Risk of sedation, hypotension, and bradycardia } \\
\text { - Limited evidence supporting use in postoperative setting } \\
\text { - Optimal dosing regimen unclear }\end{array}$ \\
\hline Ketamine & $\begin{array}{l}\text { - Reduced opioid requirements } \\
\text { - Improved pain control } \\
\text { - May reduce risk of opioid-induced } \\
\text { hyperalgesia and opioid tolerance }\end{array}$ & $\begin{array}{l}\text { - Risk of neuropsychiatric symptoms } \\
\text { - Caution in patients with cardiovascular disease, hepatic dysfunction, } \\
\text { elevated intracranial and intraocular pressure, active psychosis, and } \\
\text { pregnancy } \\
\text { - Optimal dosing regimen unclear }\end{array}$ \\
\hline Intravenous lidocaine & $\begin{array}{l}\text { - Reduced opioid requirements } \\
\text { - Improved pain control } \\
\text { - Decreased risk of ileus and shorter length of } \\
\text { stay } \\
\text { - May be particularly beneficial after abdominal } \\
\text { surgery }\end{array}$ & $\begin{array}{l}\text { - Risk of toxicity requiring monitoring of plasma lidocaine levels } \\
\text { - Optimal dosing regimen unclear }\end{array}$ \\
\hline $\begin{array}{l}\text { Peripheral nerve } \\
\text { blocks }\end{array}$ & $\begin{array}{l}\text { - Reduced opioid requirements } \\
\text { - Improved pain control } \\
\text { - Faster postoperative recovery and decreased } \\
\text { length of stay }\end{array}$ & $\begin{array}{l}\text { - Risk of bleeding, nerve injury, infection, local anesthetic systemic } \\
\text { toxicity, and various site-specific complications } \\
\text { - Risk of motor blockade and impaired postoperative mobilization } \\
\text { after lower extremity surgery }\end{array}$ \\
\hline Epidural analgesia & $\begin{array}{l}\text { - Reduced opioid requirements } \\
\text { - Improved pain control } \\
\text { - Decreased risk of postoperative morbidity, } \\
\text { particularly ileus and cardiopulmonary } \\
\text { complications }\end{array}$ & $\begin{array}{l}\text { - Risk of hypotension, urinary retention, motor blockade, backache, } \\
\text { inadvertent dural puncture, neurological injury, infection, epidural } \\
\text { hematoma, and local anesthetic systemic toxicity } \\
\text { - Usually avoided in patients with coagulopathy }\end{array}$ \\
\hline
\end{tabular}

avoided due to reduced clearance of drug metabolites and other opioids should be used with caution. ${ }^{48}$ If frequent parenteral opioid administration is required, ERPs often favor the use of patient-controlled analgesia as this delivery method individualizes opioid dosing and is associated with increased patient satisfaction and pain control. ${ }^{49}$ Prior to employing traditional opioids, some ERPs may recommend the use of tramadol, which produces analgesia via weak mu opioid receptor agonism as well as serotoninnorepinephrine reuptake inhibition. ${ }^{50}$ Tramadol is associated with lower rates of certain opioid-related adverse events including constipation, respiratory depression, and abuse. $^{51}$ However, tramadol should be utilized carefully in patients with a seizure history as seizures are a known rare 
side effect. In addition, concomitant use of tramadol and other serotonergic medications may precipitate serotonin syndrome.

\section{Non-Opioid Medications Acetaminophen}

Acetaminophen is a cornerstone of multimodal postoperative pain treatment in ERPs. Its analgesic effect is thought to be primarily mediated through inhibition of the cyclooxygenase pathway, though the exact mechanism of action remains incompletely understood. ${ }^{52}$ A single dose of acetaminophen has been shown to provide $50 \%$ pain relief for four hours in about half of patients experiencing moderateto-severe acute postoperative pain. ${ }^{53,54}$ Use of acetaminophen in conjunction with nonsteroidal anti-inflammatory drugs can have an additive or even synergistic analgesic effect. $^{55}$ In addition, acetaminophen use has been associated with reduced opioid requirements during the postoperative period. ${ }^{56-60}$ ERPs generally recommend that acetaminophen be given on a scheduled basis as this leads to more consistent dosing and is associated with decreased opioid use. ${ }^{61}$ While intravenous acetaminophen is associated with more favorable pharmacokinetics including faster onset and higher plasma and cerebrospinal fluid levels compared to oral and rectal acetaminophen, it does not provide a clear benefit with regard to analgesic efficacy and patient outcomes. ${ }^{62,63}$ Therefore, use of oral acetaminophen is generally preferred in patients that are able to tolerate oral intake while intravenous acetaminophen is useful in patients who are unable to tolerate oral intake or have impaired gastrointestinal tract function. ${ }^{63}$ Overall, acetaminophen is well-tolerated with its most concerning adverse effect being hepatotoxicity at higher doses and in patients with liver insufficiency. Given its favorable safety profile and the strong evidence supporting its use for postoperative pain treatment, almost all ERPs will recommend the routine use of acetaminophen in postoperative analgesia regimens.

\section{Nonsteroidal Anti-Inflammatory Drugs}

Nonsteroidal anti-inflammatory drugs (NSAIDs), such as ibuprofen, ketorolac, and celecoxib, produce analgesia by inhibiting the cyclooxygenase enzyme and disrupting prostaglandin synthesis. NSAIDs are effective treatments for postoperative pain and important adjuncts in a multimodal analgesia regimen for the treatment of postoperative pain. ${ }^{64-66}$ When used in conjunction with opioids in the postoperative period, NSAIDs are associated with reduced opioid consumption and improved pain control. ${ }^{54,58,59,67,68}$ Combining NSAIDs with acetaminophen produces an additive or potentially synergistic analgesic effect. ${ }^{55,67}$ In addition, NSAID use may be associated with a reduced risk of opioid-related side effects, including nausea, vomiting, and sedation. ${ }^{33,35,36,59}$ Although NSAIDs are generally well-tolerated, they are associated with an increased risk of gastrointestinal ulceration, bleeding, and renal impairment. ${ }^{59,69,70}$ The use of NSAIDs that selectively inhibit the cyclooxygenase-2 (COX-2) enzyme, such as celecoxib, may reduce the risk of gastrointestinal events and bleeding. However, COX-2 inhibitors can increase the risk of cardiovascular adverse events and are typically avoided after cardiac surgery. ${ }^{71}$ Some studies suggest that NSAIDs may result in bone nonunion after spinal fusions, although the overall body of evidence remains inconclusive. ${ }^{72-74}$ Due to the lack of strong evidence that short term use of NSAIDs in the perioperative setting affects bone fusion, the ERAS Society continues to recommend NSAID use after spinal surgery. ${ }^{75}$ Similarly, there is ongoing debate regarding the association between NSAID use and increased risk of anastomotic leaks after colorectal surgery. ${ }^{76-80}$ Despite these potential risks, many ERPs will recommend the use of NSAIDs unless contraindicated given the strong evidence supporting their efficacy in the treatment of postoperative pain.

\section{Gabapentinoids}

Gabapentinoids, such as gabapentin and pregabalin, are antiepileptic medications that produce analgesia through inhibition of voltage-gated calcium channels. These medications were traditionally used in the management of chronic neuropathic pain. However, some studies suggest that perioperative use of gabapentinoids may reduce acute postoperative pain, opioid consumption, and postoperative nausea and vomiting. ${ }^{75-87}$ In addition, perioperative gabapentinoid use may also reduce the risk of developing persistent postsurgical pain although the evidence for this effect remains insufficient. ${ }^{88,89}$ Based on these findings, gabapentinoids have been included as part of a multimodal analgesia regimen in some ERPs. However, other studies have called into question the benefit of gabapentinoid use in the perioperative setting as they are associated with adverse effects, and their analgesic and opioid-sparing effects may in fact be clinically insignificant. ${ }^{90-93}$ In particular, use of gabapentinoids has been linked to sedation, visual disturbances, and dizziness that can hinder early 
postoperative mobilization and delay recovery. ${ }^{81-87,90-92}$ In addition, perioperative gabapentin use has been associated with risk of respiratory depression, especially in older patients and those receiving higher doses of opioids. ${ }^{94}$ Overall, the quality of evidence supporting the perioperative use of gabapentinoids remains low, and optimal dosing has not been clearly established. Furthermore, gabapentinoids are currently only available in oral formulations, which may limit their use in the acute postoperative setting. Therefore, while gabapentinoids are a potential opioid-sparing adjunct for management of postoperative pain, the risks and benefits of their use should be carefully considered for each individual patient. In particular, given their side effect profile, gabapentinoids should be used with caution in elderly patients as well as patients with renal dysfunction, which often necessitates dose reduction.

\section{Alpha-2 Agonists}

Alpha-2 agonists, such as clonidine and dexmedetomidine, produce analgesia by stimulating alpha- 2 receptors in the dorsal horn of the spinal cord and reducing transmission of nociceptive signals. While these medications can be administered via multiple routes, for postoperative pain management, clonidine is often given intravenously or orally while dexmedetomidine is typically administered intravenously. Clonidine and dexmedetomidine can also be used as adjuvants in epidurals and peripheral nerve blocks to potentially improve and prolong analgesia, although data supporting these benefits is limited. ${ }^{95-99}$ Some ERPs may utilize clonidine or dexmedetomidine as an analgesic adjust for postoperative pain management as some evidence suggests that alpha-2 agonists have opioid-sparing properties. ${ }^{100,101}$ In particular, recent studies suggest postoperative dexmedetomidine infusions may reduce opioid consumption and opioid-related adverse effects. ${ }^{102,103}$ While the benefits of intraoperative use of alpha-2 agonists, particularly dexmedetomidine, are well-studied, the evidence supporting the use of alpha- 2 agonists in the postoperative setting remains scarce and optimal dosing regimens have not been identified. Common adverse effects of alpha-2 agonists include sedation, hypotension, and bradycardia. These risks should be considered when including alpha-2 agonists in a postoperative analgesia regimen given the limited evidence supporting their use in the postoperative setting.

\section{Ketamine}

Ketamine is a dissociative anesthetic that antagonizes $\mathrm{N}$-methyl-D-aspartate (NMDA) receptors in the brain and spinal cord to reduce transmission of pain signals. ${ }^{104}$ Intravenous ketamine infusions at subanesthetic doses have been shown to reduce opioid consumption and improve pain control without causing major adverse effects. ${ }^{105-110}$ The addition of ketamine to an opioid regimen has also been shown to reduce the incidence of postoperative nausea and vomiting. ${ }^{107-109,111}$ Furthermore, ketamine may prevent the development of opioidinduced hyperalgesia and opioid tolerance. ${ }^{112}$ However, it remains unclear whether perioperative ketamine use reduces the risk of developing persistent postsurgical pain. ${ }^{89,113}$ The most common adverse effects associated with use of subanesthetic doses of ketamine in the postoperative setting are neuropsychiatric symptoms, such as hallucinations and nightmares. ${ }^{105}$ Poorly controlled cardiovascular disease, hepatic dysfunction, elevated intracranial and intraocular pressure, active psychosis, and pregnancy are considered relative contraindications to ketamine use. ${ }^{114}$ As part of an ERP, ketamine infusions can be used as an analgesic adjunct for those with moderate-to-severe pain who have failed initial treatment options. Because ketamine at subanesthetic doses does not suppress airway reflexes and preserves spontaneous respirations, it can be used to reduce opioid intake in patients at risk for respiratory depression, such as those with obstructive sleep apnea. Ketamine may also be a particularly useful analgesic adjunct in patients who are opioid tolerant. ${ }^{115,116}$

\section{Intravenous Lidocaine}

Lidocaine is an amide local anesthetic that has analgesic, anti-inflammatory, and anti-hyperalgesic properties when administered intravenously. ${ }^{117}$ Some studies suggest that lidocaine infusions can reduce postoperative pain and opioid intake, especially after abdominal surgeries. ${ }^{118-122}$ In addition, lidocaine infusions may be associated with decreased risk for postoperative nausea, vomiting, and ileus as well as shorter duration of hospital stay. ${ }^{118-122}$ Based on these data, some ERPs may utilize lidocaine infusions as part of a multimodal analgesia regimen for moderate-to-severe pain, particularly after abdominal surgeries. However, a Cochrane review found insufficient evidence to confirm the benefit of lidocaine infusions for postoperative pain control and recovery. ${ }^{123}$ In addition, 
optimal dosing and infusion duration have not been established. Therefore, some uncertainty remains regarding the routine use of lidocaine infusions for postoperative pain management. Although lidocaine has a narrow therapeutic index, toxicity appears to be very rare with infusions. ${ }^{119-}$ 122 The risk of lidocaine toxicity is directly related to plasma lidocaine levels, which should be monitored during infusions.

\section{Regional Anesthesia Techniques Peripheral Nerve Blocks}

Peripheral nerve blocks (PNBs) target local anesthetic medications directly to peripheral nerves to provide analgesia. Commonly used PNBs include brachial plexus blocks for upper extremity surgeries, paravertebral blocks for thoracic surgeries, transversus abdominis plane (TAP) blocks for abdominal surgeries, and femoral and sciatic nerve blocks for lower extremity surgeries. Both singleshot PNBs and continuous PNBs can be utilized to manage postoperative pain. Single-shot PNBs are primarily limited by a short duration of action that is typically less than twenty-four hours. The addition of adjuvants, such as dexamethasone, dexmedetomidine, clonidine, and buprenorphine, may prolong the analgesia provided by singleshot PNBs, although further studies are warranted. ${ }^{97}$ There is an increasing number of studies examining the use of liposomal bupivacaine in PNBs and its effect on prolonging analgesia or improves outcomes compared to other local anesthetics. ${ }^{124,125}$ Continuous PNBs allow for a longer duration of analgesia compared to single-shot PNBs by delivering a constant local anesthetic infusion via a perineural catheter. Continuous PNBs are associated with improved pain control, decreased opioid consumption, and higher patient satisfaction compared to singleshot PNBs. ${ }^{126}$ Patients who receive continuous PNBs may even be discharged home with ambulatory infusion pumps for continued pain control.

PNBs are associated with a number of benefits in the perioperative setting including improved postoperative pain control, reduced opioid consumption, quicker postoperative recovery, decreased duration of hospital stay, lower risk of opioid-related adverse effects, and increased patient satisfaction. ${ }^{127-131}$ In some instances, PNBs may be associated with lower rate of complications, such as hypotension, compared to epidural analgesia. ${ }^{132,133}$ PNBs may also reduce the risk of developing persistent postoperative pain. ${ }^{134}$ However, PNBs do not appear to reduce the risk of long-term opioid use after surgery. ${ }^{41,42,135}$ Given their clear benefits in the perioperative setting, ERPs may recommend the use of PNBs as part of a multimodal analgesia regimen. However, a potential complication of PNBs is motor blockade, which may lead to delayed postoperative mobilization, increased risk of falls, and prolonged hospital course. ${ }^{136-138}$ Therefore, the use of PNBs for postoperative pain control after certain lower extremity surgeries is controversial. Although the use of PNBs in total knee and hip arthroplasties is somewhat controversial due to the risk of motor blockade, ${ }^{139}$ the International Consensus on AnesthesiaRelated Outcomes after Surgery (ICAROS) group recommends the use of PNBs in total knee and hip arthroplasties based on their meta-analysis demonstrating that use of PNBs in these surgeries was associated with lower risk for a variety of complications including cognitive dysfunction, cardiopulmonary complications, surgical site infections, thromboembolic events, and blood transfusions. ${ }^{140}$ Similarly, the Agency for Healthcare Research and Quality (AHRQ) recommends the use of PNBs in total knee and hip arthroplasties given their numerous demonstrated benefits. $^{141}$ Some evidence suggests that motor-sparing PNBs may preserve lower extremity muscle strength and reduce the risk of complications associated with motor blockade, although further research is needed to elucidate the optimal strategy for their use. ${ }^{142-143}$ Other complications associated with PNBs include bleeding, nerve injury, infection, and local anesthetic systemic toxicity. Individual PNBs may also be associated with site-specific complications, such as pneumothorax with brachial plexus blocks and intraperitoneal organ injury with TAP blocks. Ultrasound guidance for PNB placement reduces the risk of complications as well as improves block quality and performance time. ${ }^{144,145}$ Overall, PNBs can be effective interventions for the management of postoperative pain in ERPs but the risks, benefits, and suitability of specific PNBs should be considered in the context of the individual patient and procedure.

\section{Epidural Analgesia}

Epidural analgesia involves injection of local anesthetics with or without adjuvants into the epidural space and can be used to manage postoperative pain after a variety of thoracic, abdominal, pelvic, and lower extremity surgeries. Compared to opioid-based treatment regimens, epidural analgesia is associated with more effective postoperative pain control as well as decreased postoperative morbidity 
and mortality. ${ }^{146-152}$ In particular, epidural analgesia may lead to quicker return of bowel function and reduce the risk of cardiac and respiratory complications after surgery. ${ }^{148-151}$ However, the effect of epidural analgesia on duration of hospitalization remains unclear. ${ }^{147,149}$ Epidural analgesia may also reduce the risk of developing persistent postoperative pain. ${ }^{134}$ Given its demonstrated benefits in the postoperative period, epidural analgesia can be a valuable part of an opioid-sparing, multimodal analgesia regimen. However, the use of epidurals must be weighed against their potential adverse effects. Risks of epidural catheter placement include backache, inadvertent dural puncture, nerve or spinal cord injury, infection, epidural hematoma, and local anesthetic systemic toxicity. Epidural analgesia may also lead to hypotension, urinary retention, and motor blockade - all of which can delay return to functionality and hospital discharge. In addition, the administration of epidural opioid medications can lead to systemic absorption and opioid-related adverse effects such as nausea, vomiting, pruritus, and respiratory depression. As a result, recommendations for the use of epidural analgesia in ERPs are often procedure specific. For example, the ERAS Society generally recommends the use of epidural analgesia in open gastrointestinal surgeries, open radical cystectomies, and open gynecologic surgeries but not necessarily in hip and knee replacement surgeries due to the risk of motor blockade impairing postoperative mobilization or open liver surgeries due in part to concern for postoperative coagulopathy delaying epidural catheter removal. ${ }^{139,153-159}$ In addition, the benefits of epidural analgesia in laparoscopic surgery are less clear compared to open surgeries. ${ }^{153,154,160}$ When utilizing epidural analgesia, individual risk-benefit analyses must be performed. Epidural analgesia can be particularly advantageous in patients at high risk of ileus, cardiac complications, or pulmonary complications. However, in other patients, the risk of hypotension and subsequent need for intravenous fluid or vasopressor support may necessitate the use of alternative analgesic modalities such as TAP or paravertebral peripheral nerve blocks. ${ }^{132,133}$

\section{Limitations and Directions for Future Research}

This article is a narrative review of the literature rather than a systematic review. We focus only on analgesic interventions commonly utilized by ERPs in the perioperative setting. There are numerous other pharmacologic and non-pharmacologic interventions not discussed in this article currently being investigated for the treatment of postoperative pain that may ultimately be useful in ERPs, ranging from serotonin-norepinephrine reuptake inhibitors to novel peripheral nerve blocks to music therapy. These emerging interventions represent important areas for future research. In addition, there are preemptive analgesic techniques, such as preoperative acetaminophen dosing, and intraoperative interventions, such as esmolol infusions and local anesthetic wound infiltration, that have important implications for postoperative pain control but are beyond the scope of this review. This article demonstrates that there are a variety of evidence-based interventions routinely used for postoperative pain management in ERPs, and an important direction for future research is identifying the ideal combination of these various modalities for specific procedures and patient populations. Additional research is also needed to assess the feasibility and outcomes associated with opioid-free postoperative analgesia as well as the optimal strategies to achieve this goal.

\section{Conclusions}

Postoperative pain is often suboptimally treated and remains a challenge to manage. ERPs generally utilize a multimodal, opioid-sparing approach in the treatment of postoperative pain. While opioids remain an important treatment option for postoperative pain, ERPs employ a variety of non-opioid systemic medications and regional anesthetic techniques with the goal of minimizing opioid consumption, reducing risk of opioid-related adverse effects, and improving postoperative outcomes. While strong evidence supports this multimodal, opioid-sparing strategy, the data supporting specific modalities commonly utilized in ERPs to manage postoperative pain continues to evolve rapidly and knowledge gaps and controversies remain. As a result, there are numerous opportunities for future research, and the risks and benefits of specific treatment options should always be considered in the context of the individual patient and procedure.

\section{Funding}

There is no funding to report.

\section{Disclosure}

Richard D. Urman reports funding/fees from Heron, Merck, Medtronic/Covidien, Pfizer, AcelRx. He is vice president of the ERAS USA Society. Other authors report no conflicts of interest. 


\section{References}

1. Institute of Medicine (US) Committee on Advancing Pain Research, Care, and Education. Relieving Pain in America: A Blueprint for Transforming Prevention, Care, Education, and Research. Washington (DC): National Academies Press (US); 2011.

2. Apfelbaum JL, Chen C, Mehta SS, Gan TJ. Postoperative pain experience: results from a national survey suggest postoperative pain continues to be undermanaged. Anesth Analg. 2003;97 (2):534-540. doi:10.1213/01.ANE.0000068822.10113.9E

3. Gan TJ. Poorly controlled postoperative pain: prevalence, consequences, and prevention. J Pain Res. 2017;10:2287-2298. doi:10.2147/JPR.S144066

4. Coppes OJM, Yong RJ, Kaye AD, Urman RD. Patient and surgery-related predictors of acute postoperative pain. Curr Pain Headache Rep. 2020;24(4):12. doi:10.1007/s11916-020-0844-3

5. Kalkman JC, Visser K, Moen J, Bonsel JG, Grobbee ED, Moons MKG. Preoperative prediction of severe postoperative pain. Pain. 2003;105(3):415-423. doi:10.1016/S0304-3959(03)00252-5

6. Yang MMH, Hartley RL, Leung AA, et al. Preoperative predictors of poor acute postoperative pain control: a systematic review and meta-analysis. BMJ Open. 2019;9(4). doi:10.1136/bmjopen-2018025091

7. Wheeler M, Oderda GM, Ashburn MA, Lipman AG. Adverse events associated with postoperative opioid analgesia: a systematic review. J Pain. 2002;3(3):159-180. doi:10.1054/jpai.2002.123652

8. Brat GA, Agniel D, Beam A, et al. Postsurgical prescriptions for opioid naive patients and association with overdose and misuse: retrospective cohort study. BMJ. 2018;360:j5790. doi:10.1136/bmj.j5790

9. Elhassan A, Ahmed A, Awad H, et al. The evolution of surgical enhanced recovery pathways: a review. Curr Pain Headache Rep. 2018;22(11):74. doi:10.1007/s11916-018-0727-z

10. Stenberg E, Dos Reis Falcão LF, O'Kane M, Liem R, Pournaras DJ, Salminen P, Urman RD, Wadhwa A, Gustafsson UO, Thorell A. Guidelines for Perioperative Care in Bariatric Surgery: Enhanced Recovery After Surgery (ERAS) Society Recommendations: A 2021 Update. World J Surg. 2022 Jan 4. doi:10.1007/s00268-02106394-9. Epub ahead of print. PMID: 34984504.

11. Thiele RH, Raghunathan K, Brudney CS, Lobo DN, Martin D, Senagore A, Cannesson M, Gan TJ, Mythen MMG, Shaw AD, Miller TE; Perioperative Quality Initiative (POQI) I Workgroup. Correction to: American Society for Enhanced Recovery (ASER) and Perioperative Quality Initiative (POQI) joint consensus statement on perioperative fluid management within an enhanced recovery pathway for colorectal surgery.. Perioper Med (Lond). 2018 Apr 10;7:5. doi:10.1186/s13741-018-0085-8. Erratum for: Perioper Med (Lond). 2016 Sep 17;5:24. PMID: 29644051; PMCID: PMC5891923.

12. Robin F, Newman N, Garneau S, Roy M. PROSPECT guidelines for total hip arthroplasty: a systematic review and procedurespecific postoperative pain management recommendations.. Anaesthesia. 2021 Oct;76(10):1424. doi:10.1111/anae.15541. Epub 2021 Jul 12. PMID: 34251675.

13. Beverly A, Kaye AD, Ljungqvist O, Urman RD. Essential Elements of Multimodal Analgesia in Enhanced Recovery After Surgery (ERAS) Guidelines.. Anesthesiol Clin. 2017 35(2):e115e143. doi:10.1016/j.anclin.2017.01.018. PMID: 28526156.

14. McEvoy MD, Scott MJ, Gordon DB, Grant SA, Thacker JKM, Wu CL, Gan TJ, Mythen MG, Shaw AD, Miller TE; Perioperative Quality Initiative (POQI) I Workgroup. American Society for Enhanced Recovery (ASER) and Perioperative Quality Initiative (POQI) joint consensus statement on optimal analgesia within an enhanced recovery pathway for colorectal surgery: part 1-from the preoperative period to PACU.. Perioper Med (Lond). 2017 Apr 13;6:8. doi:10.1186/s13741-017-0064-5. PMID: 28413629; PMCID: PMC5390366.
15. Helander EM, Webb MP, Bias M, Whang EE, Kaye AD, Urman RD. Use of Regional Anesthesia Techniques: Analysis of Institutional Enhanced Recovery After Surgery Protocols for Colorectal Surgery.. J Laparoendosc Adv Surg Tech A. 201727 (9):898-902. doi:10.1089/lap.2017.0339. Epub 2017 Jul 25. PMID: 28742434.

16. Oderda GM, Gan TJ, Johnson BH, Robinson SB. Effect of opioid-related adverse events on outcomes in selected surgical patients. J Pain Palliat Care Pharmacother. 2013;27(1):62-70. doi:10.3109/15360288.2012.751956

17. Shafi S, Collinsworth AW, Copeland LA, et al. Association of opioid-related adverse drug events with clinical and cost outcomes among surgical patients in a large integrated health care delivery system. JAMA Surg. 2018;153(8):757-763. doi:10.1001/ jamasurg.2018.1039

18. Colvin LA, Bull F, Hales TG. Perioperative opioid analgesia-when is enough too much? A review of opioid-induced tolerance and hyperalgesia. Lancet. 2019;393 (10180):1558-1568. doi:10.1016/S0140-6736(19)30430-1

19. Hah JM, Bateman BT, Ratliff J, Curtin C, Sun E. Chronic opioid use after surgery: implications for perioperative management in the face of the opioid epidemic. Anesth Analg. 2017;125(5):1733-1740. doi:10.1213/ANE.0000000000002458

20. Carrol R, Angst MS, Clark JD. Management of perioperative pain in patients chronically consuming opioids. Reg Anesth Pain Med. 2004;29(6):576-591.

21. Edwards DA, Hedrick TL, Jayaram J, et al. American Society for Enhanced Recovery and Perioperative Quality Initiative Joint Consensus statement on perioperative management of patients on preoperative opioid therapy. Anesth Analg. 2019;129 (2):553-566. doi:10.1213/ANE.0000000000004018

22. Talboys R, Mak M, Modi N, Fanous N, Cutts S. Enhanced recovery programme reduces opiate consumption in hip hemiarthroplasty. Eur J Orthop Surg Traumatol. 2016;26 (2):177-181. doi:10.1007/s00590-015-1722-2

23. Warren JA, Stoddard C, Hunter AL, et al. Effect of multimodal analgesia on opioid use after open ventral hernia repair. $J$ Gastrointest Surg. 2017;21(10):1692-1699. doi:10.1007/ s11605-017-3529-4

24. King AB, Spann MD, Jablonski P, Wanderer JP, Sandberg WS, McEvoy MD. An enhanced recovery program for bariatric surgical patients significantly reduces perioperative opioid consumption and postoperative nausea. Surg Obes Relat Dis. 2018;14 (6):849-856. doi:10.1016/j.soard.2018.02.010

25. Page AJ, Gani F, Crowley KT, et al. Patient outcomes and provider perceptions following implementation of a standardized perioperative care pathway for open liver resection. Br J Surg. 2016;103(5):564-571. doi:10.1002/bjs. 10087

26. Offodile AC, Gu C, Boukovalas S, et al. Enhanced recovery after surgery (ERAS) pathways in breast reconstruction: systematic review and meta-analysis of the literature. Breast Cancer Res Treat. 2019;173(1):65-77. doi:10.1007/s10549-018-4991-8

27. Schwartz AR, Lim S, Broadwater G, et al. Reduction in opioid use and postoperative pain scores after elective laparotomy with implementation of enhanced recovery after surgery protocol on a gynecologic oncology service. Int J Gynecol Cancer. 2019;29 (5):935-943. doi:10.1136/ijgc-2018-000131

28. Shinnick JK, Ruhotina M, Has P, et al. Enhanced recovery after surgery for cesarean delivery decreases length of hospital stay and opioid consumption: a quality improvement initiative. $\mathrm{Am}$ $J$ Perinatol. 2021;38(S 01):e215-e223. doi:10.1055/s-00401709456

29. Dietz N, Sharma M, Adams S, et al. Enhanced recovery after surgery (ERAS) for spine surgery: a systematic review. World Neurosurg. 2019;130:415-426. doi:10.1016/j.wneu.2019.06.181 
30. Flanders TM, Ifrach J, Sinha S, et al. Reduction of postoperative opioid use after elective spine and peripheral nerve surgery using an enhanced recovery after surgery program. Pain Med. 2020;21 (12):3283-3291. doi:10.1093/pm/pnaa233

31. Adeyemo EA, Aoun SG, Barrie U, et al. Enhanced recovery after surgery reduces postoperative opioid use and 90-day readmission rates after open thoracolumbar fusion for adult degenerative deformity. Neurosurgery. 2021;88(2):295-300. doi:10.1093/neuros/nyaa399

32. Zhao SZ, Chung F, Hanna DB, Raymundo AL, Cheung RY, Chen C. Dose-response relationship between opioid use and adverse effects after ambulatory surgery. J Pain Symptom Manage. 2004;28 (1):35-46. doi:10.1016/j.jpainsymman.2003.11.001

33. Marret E, Kurdi O, Zufferey P, Bonnet F, Warltier D. Effects of nonsteroidal antiinflammatory drugs on patient-controlled analgesia morphine side effects: meta-analysis of randomized controlled trials. Anesthesiology. 2005;102(6):1249-1260. doi:10.1097/ 00000542-200506000-00027

34. Fayaz MK, Abel RJ, Pugh SC, Hall JE, Djaiani G, Mecklenburgh JS. Opioid-sparing effects of diclofenac and paracetamol lead to improved outcomes after cardiac surgery. J Cardiothorac Vasc Anesth. 2004;18(6):742-747. doi:10.1053/j. jvca.2004.08.012

35. Ng A, Parker J, Toogood L, Cotton BR, Smith G. Does the opioid-sparing effect of rectal diclofenac following total abdominal hysterectomy benefit the patient? Br J Anaesth. 2002;88 (5):714-716. doi:10.1093/bja/88.5.714

36. Gan TJ, Joshi GP, Zhao SZ, Hanna DB, Cheung RY, Chen C. Presurgical intravenous parecoxib sodium and follow-up oral valdecoxib for pain management after laparoscopic cholecystectomy surgery reduces opioid requirements and opioid-related adverse effects. Acta Anaesthesiol Scand. 2004;48(9):1194-1207. doi:10.1111/j.1399-6576.2004.00495.x

37. Bloom DA, Manjunath AK, Gualtieri AP, et al. Patient satisfaction after total hip arthroplasty is not influenced by reductions in opioid prescribing. $J$ Arthroplasty. 2021;36(7S):S250-S257. doi:10.1016/j.arth.2021.02.009

38. Padilla JA, Gabor JA, Schwarzkopf R, Davidovitch RI. A novel opioid-sparing pain management protocol following total hip arthroplasty: effects on opioid consumption, pain severity, and patient-reported outcomes. J Arthroplasty. 2019;34 (11):2669-2675. doi:10.1016/j.arth.2019.06.038

39. Liu VX, Eaton A, Lee DC, et al. Postoperative opioid use before and after enhanced recovery after surgery program implementation. Ann Surg. 2019;270(6):e69-e71. doi:10.1097/ SLA.0000000000003409

40. Ladha KS, Patorno E, Liu J, Bateman BT. Impact of perioperative epidural placement on postdischarge opioid use in patients undergoing abdominal surgery. Anesthesiology. 2016;124(2):396-403. doi:10.1097/ALN.0000000000000952

41. Sun EC, Bateman BT, Memtsoudis SG, Neuman MD, Mariano ER, Baker LC. Lack of association between the use of nerve blockade and the risk of postoperative chronic opioid use among patients undergoing total knee arthroplasty: evidence from the marketscan database. Anesth Analg. 2017;125(3):999-1007. doi:10.1213/ANE.000000000 0001943

42. Mueller KG, Memtsoudis SG, Mariano ER, Baker LC, Mackey S, Sun EC. Lack of association between the use of nerve blockade and the risk of persistent opioid use among patients undergoing shoulder arthroplasty: evidence from the marketscan database. Anesth Analg. 2017;125(3):1014-1020. doi:10.1213/ANE.000 0000000002031
43. Echeverria-Villalobos M, Stoicea N, Todeschini AB, et al. Enhanced recovery after surgery (ERAS): a perspective review of postoperative pain management under ERAS pathways and its role on opioid crisis in the United States. Clin J Pain. 2020;36 (3):219-226. doi:10.1097/AJP.0000000000000792

44. Fiore JF, Olleik G, El-Kefraoui C, et al. Preventing opioid prescription after major surgery: a scoping review of opioid-free analgesia. Br J Anaesth. 2019;123(5):627-636. doi:10.1016/j. bja.2019.08.014

45. Pergolizzi JV, Magnusson P, LeQuang JA, et al. Can NSAIDs and acetaminophen effectively replace opioid treatment options for acute pain? Expert Opin Pharmacother. 2021;22(9):1119-1126. doi:10.1080/14656566.2021.1901885

46. Shanthanna H, Ladha KS, Kehlet H, Joshi G. Perioperative opioid administration. Anesthesiology. 2021;134(4):645-659. doi:10.10 97/ALN.0000000000003572

47. Miller M, Barber CW, Leatherman S, et al. Prescription opioid duration of action and the risk of unintentional overdose among patients receiving opioid therapy. JAMA Intern Med. 2015;175 (4):608-615.

48. Dean M. Opioids in renal failure and dialysis patients. $J$ Pain Symptom Manage. 2004;28(5):497-504. doi:10.1016/j. jpainsymman.2004.02.021

49. McNicol ED, Ferguson MC, Hudcova J. Patient controlled opioid analgesia versus non-patient controlled opioid analgesia for postoperative pain. Cochrane Database Syst Rev. 2015;2015(6):CD003348.

50. Scott MJ, McEvoy MD, Gordon DB, et al. American Society for Enhanced Recovery (ASER) and Perioperative Quality Initiative (POQI) joint consensus statement on optimal analgesia within an enhanced recovery pathway for colorectal surgery: part 2-from PACU to the transition home. Perioper Med (Lond). 2017;6:7. doi:10.1186/s13741-017-0063-6

51. Grond S, Sablotzki A. Clinical pharmacology of tramadol. Clin Pharmacokinet. 2004;43(13):879-923. doi:10.2165/00003088200443130-00004

52. Ohashi N, Kohno T. Analgesic effect of acetaminophen: a review of known and novel mechanisms of action. Front Pharmacol. 2020;11:580289. doi:10.3389/fphar.2020.580289

53. Toms L, McQuay HJ, Derry S, Moore RA. Single dose oral paracetamol (Acetaminophen) for postoperative pain in adults. Cochrane Database Syst Rev. 2008;(4). doi:10.1002/14651858. CD004602.pub2

54. Derry CJ, Derry S, Moore RA. Single dose oral ibuprofen plus paracetamol (Acetaminophen) for acute postoperative pain. Cochrane Database Syst Rev. 2013;2013(6): CD010210.

55. Ong CK, Seymour RA, Lirk P, Merry AF. Combining paracetamol (Acetaminophen) with nonsteroidal antiinflammatory drugs: a qualitative systematic review of analgesic efficacy for acute postoperative pain. Anesth Analg. 2010;110(4):1170-1179. doi:10.1213/ANE.0b013e3181 cf9281

56. Remy C, Marret E, Bonnet F. Effects of acetaminophen on morphine side-effects and consumption after major surgery: meta-analysis of randomized controlled trials. $\mathrm{Br} J$ Anaesth. 2005;94(4):505-513. doi:10.1093/bja/aei085

57. Jebaraj B, Maitra S, Baidya DK, Khanna P. Intravenous paracetamol reduces postoperative opioid consumption after orthopedic surgery: a systematic review of clinical trials. Pain Res Treat. 2013;2013:1-6. doi:10.1155/2013/402510

58. Maund E, McDaid C, Rice S, Wright K, Jenkins B, Woolacott N. Paracetamol and selective and non-selective non-steroidal anti-inflammatory drugs for the reduction in morphine-related side-effects after major surgery: a systematic review. $\mathrm{Br}$ J Anaesth. 2011;106(3):292-297. doi:10.1093/bja/aeq406 
59. Elia N, Lysakowski C, Tramèr M. Does multimodal analgesia with acetaminophen, nonsteroidal antiinflammatory drugs, or selective cyclooxygenase-2 inhibitors and patient-controlled analgesia morphine offer advantages over morphine alone? Meta-analyses of randomized trials. Anesthesiology. 2005;103 (6):1296-1304. doi:10.1097/00000542-200512000-00025

60. McNicol ED, Ferguson MC, Haroutounian S, Carr DB, Schumann R. Single dose intravenous paracetamol or intravenous propacetamol for postoperative pain. Cochrane Database Syst Rev. 2016;2016(5):CD007126.

61. Valentine AR, Carvalho B, Lazo TA, Riley ET. Scheduled acetaminophen with as-needed opioids compared to as-needed acetaminophen plus opioids for post-cesarean pain management. Int $J$ Obstet Anesth. 2015;24(3):210-216. doi:10.1016/j. ijoa.2015.03.006

62. Singla NK, Parulan C, Samson R, et al. Plasma and cerebrospinal fluid pharmacokinetic parameters after single-dose administration of intravenous, oral, or rectal Acetaminophen. Pain Pract. 2012;12(7):523-532. doi:10.1111/j.1533-2500.2012.00 556.x

63. Jibril F, Sharaby S, Mohamed A, Wilby KJ. Intravenous versus oral acetaminophen for pain: systematic review of current evidence to support clinical decision-making. Can J Hosp Pharm. 2015;68(3):238-247. doi:10.4212/cjhp.v68i3.1458

64. Derry CJ, Derry S, Moore RA, McQuay HJ. Single dose oral ibuprofen for acute postoperative pain in adults. Cochrane Database Syst Rev. 2009;2009(3):CD001548.

65. Derry S, Moore RA. Single dose oral celecoxib for acute postoperative pain in adults. Cochrane Database Syst Rev. 2013;(10): CD004233.

66. McNicol ED, Ferguson MC, Schumann R. Single-dose intravenous ketorolac for acute postoperative pain in adults. Cochrane Database Syst Rev. 2021;17(5):CD013263.

67. Wong I, St John-Green C, Walker SM, Lonnqvist P-A. Opioidsparing effects of perioperative paracetamol and nonsteroidal anti-inflammatory drugs (NSAIDs) in children. Paediatr Anaesth. 2013;23(6):475-495. doi:10.1111/pan.12163

68. Bainbridge D, Cheng DC, Martin JE, Novick R. NSAIDanalgesia, pain control and morbidity in cardiothoracic surgery. Can J Anaesthes. 2006;53(1):46-59. doi:10.1007/BF03021527

69. Bell S, Rennie T, Marwick CA, Davey P. Effects of peri-operative nonsteroidal anti-inflammatory drugs on post-operative kidney function for adults with normal kidney function. Cochrane Database Syst Rev. 2018;11(11). doi:10.1002/14651858. CD011274.pub2

70. Strom BL, Berlin JA, Kinman JL, et al. Parenteral ketorolac and risk of gastrointestinal and operative site bleeding. A postmarketing surveillance study. JAMA. 1996;275(5):376. doi:10.1001/jama.1996.03530290046036

71. Nussmeier NA, Whelton AA, Brown MT, et al. Complications of the COX-2 inhibitors parecoxib and valdecoxib after cardiac surgery. N Engl J Med. 2005;352(11):1081-1091. doi:10.1056/ NEJMoa050330

72. Dodwell ER, Latorre JG, Parisini E, et al. NSAID exposure and risk of nonunion: a meta-analysis of case-control and cohort studies. Calcif Tissue Int. 2010;87(3):193-202. doi:10.1007/ s00223-010-9379-7

73. Sivaganesan A, Chotai S, White-Dzuro G, McGirt MJ, Devin CJ. The effect of NSAIDs on spinal fusion: a cross-disciplinary review of biochemical, animal, and human studies. Eur Spine J. 2017;26(11):2719-2728. doi:10.1007/s00586-017-5021-y

74. Li Q, Zhang Z, Cai Z. High-dose ketorolac affects adult spinal fusion: a meta-analysis of the effect of perioperative nonsteroidal anti-inflammatory drugs on spinal fusion. Spine. 2011;36(7): E461-E468. doi:10.1097/BRS.0b013e3181dfd163
75. Debono B, Wainwright TW, Wang MY, et al. Consensus statement for perioperative care in lumbar spinal fusion: Enhanced Recovery After Surgery (ERAS(R)) Society recommendations. Spine J. 2021;21(5):729-752. doi:10.1016/ j.spinee.2021.01.001

76. Gorissen KJ, Benning D, Berghmans T, et al. Risk of anastomotic leakage with non-steroidal anti-inflammatory drugs in colorectal surgery. Br J Surg. 2012;99(5):721-727. doi:10.1002/bjs.8691

77. Hakkarainen TW, Steele SR, Bastaworous A, et al. Nonsteroidal anti-inflammatory drugs and the risk for anastomotic failure: a report from Washington State's Surgical Care and Outcomes Assessment Program (SCOAP). JAMA Surg. 2015;150(3):223. doi:10.1001/jamasurg.2014.2239

78. Kverneng Hultberg D, Angenete E, Lydrup ML, Rutegard J, Matthiessen P, Rutegard M. Nonsteroidal anti-inflammatory drugs and the risk of anastomotic leakage after anterior resection for rectal cancer. Eur J Surg Oncol. 2017;43(10):1908-1914. doi:10.1016/j.ejso.2017.06.010

79. Huang Y, Tang SR, Young CJ. Nonsteroidal anti-inflammatory drugs and anastomotic dehiscence after colorectal surgery: a meta-analysis. ANZ J Surg. 2018;88(10):959-965. doi:10.1111/ ans. 14322

80. Modasi A, Pace D, Godwin M, Smith C, Curtis B. NSAID administration post colorectal surgery increases anastomotic leak rate: systematic review/meta-analysis. Surg Endosc. 2019;33 (3):879-885. doi:10.1007/s00464-018-6355-1

81. Hurley RW, Cohen SP, Williams KA, Rowlingson AJ, Wu CL. The analgesic effects of perioperative gabapentin on postoperative pain: a meta-analysis. Reg Anesth Pain Med. 2006;31 (3):237-247. doi:10.1016/j.rapm.2006.01.005

82. Tiippana EM, Hamunen K, Kontinen VK, Kalso E. Do surgical patients benefit from perioperative gabapentin/pregabalin? A systematic review of efficacy and safety. Anesth Analg. 2007;104(6):1545-1556. doi:10.1213/01.ane.0000261517.275 32.80

83. Peng PW, Wijeysundera DN, Li CC. Use of gabapentin for perioperative pain control - a meta-analysis. Pain Res Manag. 2007;12(2):85-92. doi:10.1155/2007/840572

84. Doleman B, Heinink TP, Read DJ, Faleiro RJ, Lund JN, Williams JP. A systematic review and meta-regression analysis of prophylactic gabapentin for postoperative pain. Anaesthesia. 2015;70(10):1186-1204. doi:10.1111/anae.13179

85. Mishriky BM, Waldron NH, Habib AS. Impact of pregabalin on acute and persistent postoperative pain: a systematic review and meta-analysis. Br J Anaesth. 2015;114(1):10-31. doi:10.1093/bja/ aeu293

86. Lam DMH, Choi SW, Wong SSC, Irwin MG, Cheung CW. Efficacy of pregabalin in acute postoperative pain under different surgical categories: a meta-analysis. Medicine. 2015;94(46): e1944. doi:10.1097/MD.0000000000001944

87. Eipe N, Penning J, Yazdi F, et al. Perioperative use of pregabalin for acute pain-a systematic review and meta-analysis. Pain. 2015;156(7):1284-1300. doi:10.1097/j.pain.0000000000000173

88. Clarke H, Bonin RP, Orser BA, Englesakis M, Wijeysundera DN, Katz J. The prevention of chronic postsurgical pain using gabapentin and pregabalin: a combined systematic review and meta-analysis. Anesth Analg. 2012;115(2):428-442. doi:10.1213/ ANE.0b013e318249d36e

89. Chaparro LE, Smith SA, Moore RA, Wiffen PJ, Gilron I. Pharmacotherapy for the prevention of chronic pain after surgery in adults. Cochrane Database Syst Rev. 2013;2013(7): CD008307.

90. Fabritius ML, Geisler A, Petersen PL, et al. Gabapentin for post-operative pain management - a systematic review with meta-analyses and trial sequential analyses. Acta Anaesthesiol Scand. 2016;60(9):1188-1208. doi:10.1111/aas.12766 
91. Fabritius ML, Strøm C, Koyuncu S, et al. Benefit and harm of pregabalin in acute pain treatment: a systematic review with meta-analyses and trial sequential analyses. $\mathrm{Br} J$ Anaesth. 2017;119(4):775-791. doi:10.1093/bja/aex227

92. Verret M, Lauzier F, Zarychanski R, et al. Perioperative use of gabapentinoids for the management of postoperative acute pain: a systematic review and meta-analysis. Anesthesiology. 2020;133 (2):265-279. doi:10.1097/ALN.0000000000003428

93. Straube S, Derry S, Moore RA, Wiffen PJ, McQuay HJ. Single dose oral gabapentin for established acute postoperative pain in adults. Cochrane Database Syst Rev. 2010;2010 (5):CD008183.

94. Cavalcante AN, Sprung J, Schroeder DR, Weingarten TN. Multimodal analgesic therapy with gabapentin and its association with postoperative respiratory depression. Anesth Analg. 2017;125(1):141-146. doi:10.1213/ANE.0000000000001719

95. Pöpping DM, Elia N, Marret E, Wenk M, Tramèr MR. Clonidine as an adjuvant to local anesthetics for peripheral nerve and plexus blocks: a meta-analysis of randomized trials. Anesthesiology. 2009;111(2):406-415. doi:10.1097/ ALN.0b013e3181aae897

96. Krishnamoorthy K, Ravi S, Ganesan I. Evaluation of efficacy of epidural clonidine with $0.5 \%$ bupivacaine for postoperative analgesia for orthopaedic lower limb surgeries. J Clin Diagn Res. 2015;9(9):UC14-8. doi:10.7860/JCDR/2015/14964.6457

97. Kirksey Ma, Haskins SC, Cheng J, Liu SS, Schwentner C. Local anesthetic peripheral nerve block adjuvants for prolongation of analgesia: a systematic qualitative review. PLoS One. 2015;10(9): e0137312. doi:10.1371/journal.pone.0137312

98. Zhang X, Wang D, Shi M, Luo Y. Efficacy and safety of dexmedetomidine as an adjuvant in epidural analgesia and anesthesia: a systematic review and meta-analysis of randomized controlled trials. Clin Drug Investig. 2017;37(4):343-354. doi:10.1007/s40261016-0477-9

99. Schnabel A, Reichl SU, Weibel S, et al. Efficacy and safety of dexmedetomidine in peripheral nerve blocks: a meta-analysis and trial sequential analysis. Eur $J$ Anaesthesiol. 2018;35 (10):745-758. doi:10.1097/EJA.0000000000000870

100. Blaudszun G, Lysakowski C, Elia N, Tramèr MR. Effect of perioperative systemic $\alpha 2$ agonists on postoperative morphine consumption and pain intensity: systematic review and metaanalysis of randomized controlled trials. Anesthesiology. 2012;116(6):1312-1322. doi:10.1097/ALN.0b013e31825681cb

101. Jessen Lundorf L, Korvenius Nedergaard H, Møller AM. Perioperative dexmedetomidine for acute pain after abdominal surgery in adults. Cochrane Database Syst Rev. 2016;2. doi:10.1002/14651858.CD010358.pub2

102. Feng M, Chen X, Liu T, Zhang C, Wan L, Yao W. Dexmedetomidine and sufentanil combination versus sufentanil alone for postoperative intravenous patient-controlled analgesia: a systematic review and meta-analysis of randomized controlled trials. BMC Anesthesiol. 2019;19(1). doi:10.1186/s12871-019-0756-0

103. Peng K, Zhang J, Meng XW, Liu HY, Ji FH. Optimization of postoperative intravenous patient-controlled analgesia with opioid-dexmedetomidine combinations: an updated meta-analysis with trial sequential analysis of randomized controlled trials. Pain Physician. 2017;20(7):569-596.

104. Bell RF, Kalso EA. Ketamine for pain management. Pain Rep. 2018;3(5):e674. doi:10.1097/PR9.0000000000000674

105. Laskowski K, Stirling A, McKay WP, Lim HJ. A systematic review of intravenous ketamine for postoperative analgesia. Can J Anaesth. 2011;58(10):911-923. doi:10.1007/s12630-011-9560-0

106. Jouguelet-Lacoste J, La Colla L, Schilling D, Chelly JE. The use of intravenous infusion or single dose of low-dose ketamine for postoperative analgesia: a review of the current literature. Pain Med. 2015;16(2):383-403. doi:10.1111/pme.12619
107. Wang L, Johnston B, Kaushal A, Cheng D, Zhu F, Martin J. Ketamine added to morphine or hydromorphone patient-controlled analgesia for acute postoperative pain in adults: a systematic review and meta-analysis of randomized trials. Can $J$ Anaesth. 2016;63(3):311-325. doi:10.1007/s12630-015-0551-4

108. Brinck EC, Tiippana E, Heesen M, et al. Perioperative intravenous ketamine for acute postoperative pain in adults. Cochrane Database Syst Rev. 2018;12(12). doi:10.1002/14651858. CD012033.pub4

109. Assouline B, Tramèr MR, Kreienbühl L, Elia N. Benefit and harm of adding ketamine to an opioid in a patient-controlled analgesia device for the control of postoperative pain: systematic review and meta-analyses of randomized controlled trials with trial sequential analyses. Pain. 2016;157(12):2854-2864. doi:10.1097/j.pain.0000000000000705

110. Pendi A, Field R, Farhan SD, Eichler M, Bederman SS. Perioperative ketamine for analgesia in spine surgery: a meta-analysis of randomized controlled trials. Spine. 2018;43(5): E299-E307. doi:10.1097/BRS.0000000000002318

111. Ding X, Jin S, Niu X, et al. Morphine with adjuvant ketamine versus higher dose of morphine alone for acute pain: a meta-analysis. Int J Clin Exp Med. 2014;7(9):2504-2510.

112. Laulin JP, Maurette P, Corcuff JB, Rivat C, Chauvin M, Simonnet G. The role of ketamine in preventing fentanyl-induced hyperalgesia and subsequent acute morphine tolerance. Anesth Analg. 2002;94(5):1263-1269. doi:10.1097/ 00000539-200205000-00040

113. McNicol ED, Schumann R, Haroutounian S. A systematic review and meta-analysis of ketamine for the prevention of persistent post-surgical pain. Acta Anaesthesiol Scand. 2014;58 (10):1199-1213. doi:10.1111/aas.12377

114. Schwenk ES, Viscusi ER, Buvanendran A, et al. Consensus guidelines on the use of intravenous ketamine infusions for acute pain management from the American Society of Regional Anesthesia and Pain Medicine, the American Academy of Pain Medicine, and the American Society of Anesthesiologists. Reg Anesth Pain Med. 2018;43(5):456-466.

115. Barreveld AM, Correll DJ, Liu X, et al. Ketamine decreases postoperative pain scores in patients taking opioids for chronic pain: results of a prospective, randomized, double-blind study. Pain Med. 2013;14(6):925-934. doi:10.1111/pme.12086

116. Urban MK, Ya Deau JT, Wukovits B, Lipnitsky JY. Ketamine as an adjunct to postoperative pain management in opioid tolerant patients after spinal fusions: a prospective randomized trial. HSS J. 2008;4(1):62-65. doi:10.1007/s11420-007-9069-9

117. van der Wal SE, van den Heuvel SA, Radema SA, et al. The in vitro mechanisms and in vivo efficacy of intravenous lidocaine on the neuroinflammatory response in acute and chronic pain. Eur J Pain. 2016;20(5):655-674. doi:10.1002/ejp.794

118. Kranke P, Jokinen J, Pace NL, et al. Continuous intravenous perioperative lidocaine infusion for postoperative pain and recovery. Cochrane Database Syst Rev. 2015;(7). doi:10.1002/ 14651858.CD009642.pub2

119. Ventham NT, Kennedy ED, Brady RR, et al. Efficacy of intravenous lidocaine for postoperative analgesia following laparoscopic surgery: a meta-analysis. World J Surg. 2015;39(9):2220-2234. doi:10.1007/s00268-015-3105-6

120. Vigneault L, Turgeon AF, Côté D, et al. Perioperative intravenous lidocaine infusion for postoperative pain control: a meta-analysis of randomized controlled trials. Can J Anaesthes. 2011;58 (1):22-37. doi:10.1007/s12630-010-9407-0

121. McCarthy GC, Megalla SA, Habib AS. Impact of intravenous lidocaine infusion on postoperative analgesia and recovery from surgery: a systematic review of randomized controlled trials. Drugs. 2010;70(9):1149-1163. doi:10.2165/10898560000000000-00000 
122. Marret E, Rolin M, Beaussier M, Bonnet F. Meta-analysis of intravenous lidocaine and postoperative recovery after abdominal surgery. Br J Surg. 2008;95(11):1331-1338. doi:10.1002/bjs.6375

123. Weibel S, Jelting Y, Pace NL, et al. Continuous intravenous perioperative lidocaine infusion for postoperative pain and recovery in adults. Cochrane Database Syst Rev. 2018;6(6). doi:10.1002/14651858.CD009642.pub3

124. Hamilton TW, Athanassoglou V, Trivella M, et al. Liposomal bupivacaine peripheral nerve block for the management of postoperative pain. Cochrane Database Syst Rev. 2016;2016(8): CD011476.

125. Ilfeld BM, Eisenach JC, Gabriel RA. Clinical effectiveness of liposomal bupivacaine administered by infiltration or peripheral nerve block to treat postoperative pain. Anesthesiology. 2021;134 (2):283-344. doi:10.1097/ALN.0000000000003630

126. Bingham AE, Fu R, Horn JL, Abrahams MS. Continuous peripheral nerve block compared with single-injection peripheral nerve block: a systematic review and meta-analysis of randomized controlled trials. Reg Anesth Pain Med. 2012;37(6):583-594. doi:10.1097/AAP.0b013e31826c351b

127. Williams BA, Kentor ML, Vogt MT, et al. Economics of nerve block pain management after anterior cruciate ligament reconstruction: potential hospital cost savings via associated postanesthesia care unit bypass and same-day discharge. Anesthesiology. 2004;100(3):697-706.

128. Richman JM, Liu SS, Courpas G, et al. Does continuous peripheral nerve block provide superior pain control to opioids? A meta-analysis. Anesth Analg. 2006;102(1):248-257. doi:10.1213/ 01.ANE.0000181289.09675.7D

129. Chan EY, Fransen M, Parker DA, Assam PN, Chua N. Femoral nerve blocks for acute postoperative pain after knee replacement surgery. Cochrane Database Syst Rev. 2014;2014(5):CD009941.

130. Ullah H, Samad K, Khan FA. Continuous interscalene brachial plexus block versus parenteral analgesia for postoperative pain relief after major shoulder surgery. Cochrane Database Syst Rev. 2014;2014(2). doi:10.1002/14651858.CD007080.pub2

131. Liu Q, Chelly JE, Williams JP, Gold MS. Impact of peripheral nerve block with low dose local anesthetics on analgesia and functional outcomes following total knee arthroplasty: a retrospective study. Pain Med. 2015;16(5):998-1006. doi:10.1111/pme.12652

132. Yeung JH, Gates S, Naidu BV, Wilson MJ, Gao Smith F. F. G. S. Paravertebral block versus thoracic epidural for patients undergoing thoracotomy. Cochrane Database Syst Rev. 2016;2 (2). doi:10.1002/14651858.CD009121.pub2

133. Desai N, El-Boghdadly K, Albrecht E. Epidural vs. transversus abdominis plane block for abdominal surgery - a systematic review, meta-analysis and trial sequential analysis. Anaesthesia. 2021;76(1):101-117. doi:10.1111/anae.15068

134. Weinstein EJ, Levene JL, Cohen MS, et al. Local anaesthetics and regional anaesthesia versus conventional analgesia for preventing persistent postoperative pain in adults and children. Cochrane Database Syst Rev. 2018;4(4). doi:10.1002/14651858.CD007105. pub3

135. Hamilton GM, Tierney S, Ramlogan R, McCartney CJL, Bromley LA, McIsaac DI. Persistent postoperative opioid prescription fulfillment and peripheral nerve blocks for ambulatory shoulder surgery: a retrospective cohort study. Anesthesiology. 2021;135:829-841. doi:10.1097/ALN.0000000000003962

136. Kandasami M, Kinninmonth AW, Sarungi M, Baines J, Scott NB. Femoral nerve block for total knee replacement - a word of caution. Knee. 2009;16(2):98-100. doi:10.1016/j.knee.2008.10.007

137. Ilfeld BM, Duke KB, Donohue MC. The association between lower extremity continuous peripheral nerve blocks and patient falls after knee and hip arthroplasty. Anesth Analg. 2010;111 (6):1552-1554. doi:10.1213/ANE.0b013e3181fb9507
138. Sharma S, Iorio R, Specht LM, Davies-Lepie S, Healy WL. Complications of femoral nerve block for total knee arthroplasty. Clin Orthop Relat Res. 2010;468(1):135-140. doi:10.1007/s11999-009-1025-1

139. Wainwright TW, Gill M, McDonald DA, et al. Consensus statement for perioperative care in total hip replacement and total knee replacement surgery: Enhanced Recovery After Surgery (ERAS ((R))) Society recommendations. Acta Orthop. 2020;91(1):3-19. doi:10.1080/17453674.2019.1683790

140. Memtsoudis SG, Cozowicz C, Bekeris J, et al. Peripheral nerve block anesthesia/analgesia for patients undergoing primary hip and knee arthroplasty: recommendations from the International Consensus on Anesthesia-Related Outcomes after Surgery (ICAROS) group based on a systematic review and meta-analysis of current literature. Reg Anesth Pain Med. 2021;46(11):971-985.

141. Soffin EM, Gibbons MM, Ko CY, et al. Evidence review conducted for the agency for healthcare research and quality safety program for improving surgical care and recovery: focus on anesthesiology for total hip arthroplasty. Anesth Analg. 2019;128(3):441-453.

142. Sogbein OA, Sondekoppam RV, Bryant D, et al. Ultrasoundguided motor-sparing knee blocks for postoperative analgesia following total knee arthroplasty: a randomized blinded study. J Bone Joint Surg Am. 2017;99(15):1274-1281. doi:10.2106/ JBJS.16.01266

143. Zhang Z, Wang Y, Liu Y. Effectiveness of continuous adductor canal block versus continuous femoral nerve block in patients with total knee arthroplasty: a PRISMA guided systematic review and meta-analysis. Medicine. 2019;98(48):e18056.

144. Walker KJ, McGrattan K, Aas-Eng K, Smith AF. Ultrasound guidance for peripheral nerve blockade. Cochrane Database Syst Rev. 2009;(4):CD006459. doi:10.1002/14651858.CD00 6459.pub2

145. Lewis SR, Price A, Walker KJ, McGrattan K, Smith AF. Ultrasound guidance for upper and lower limb blocks. Cochrane Database Syst Rev. 2015;2015(9). doi:10.1002/14651858. CD006459.pub3

146. Block BM, Liu SS, Rowlingson AJ, Cowan AR, Cowan JA, Wu CL. Efficacy of postoperative epidural analgesia: a meta-analysis. JAMA. 2003;290(18):2455. doi:10.1001/ jama.290.18.2455

147. Marret E, Remy C, Bonnet F. Meta-analysis of epidural analgesia versus parenteral opioid analgesia after colorectal surgery. $\mathrm{Br}$ J Surg. 2007;94(6):665-673. doi:10.1002/bjs.5825

148. Pöpping DM, Elia N, Van Aken HK, et al. Impact of epidural analgesia on mortality and morbidity after surgery: systematic review and meta-analysis of randomized controlled trials. Ann Surg. 2014;259 (6):1056-1067. doi:10.1097/SLA.0000000000000237

149. Guay J, Kopp SL, Kopp SL. Epidural local anesthetics versus opioid-based analgesic regimens for postoperative gastrointestinal paralysis, vomiting, and pain after abdominal surgery: a Cochrane review. Anesth Analg. 2016;123(6):1591-1602. doi:10.1213/ ANE.0000000000001628

150. Guay J, Kopp S. Epidural pain relief versus systemic opioid-based pain relief for abdominal aortic surgery. Cochrane Database Syst Rev. 2016;2016(1):CD005059.

151. Guay J, Kopp S. Epidural analgesia for adults undergoing cardiac surgery with or without cardiopulmonary bypass. Cochrane Database Syst Rev. 2019;3(3). doi:10.1002/14651858. CD006715.pub3

152. Salicath JH, Yeoh EC, Bennett MH. Epidural analgesia versus patient-controlled intravenous analgesia for pain following intra-abdominal surgery in adults. Cochrane Database Syst Rev. 2018;8(8). doi:10.1002/14651858.CD010434.pub2 
153. Feldheiser A, Aziz O, Baldini G, et al. Enhanced Recovery After Surgery (ERAS) for gastrointestinal surgery, part 2: consensus statement for anaesthesia practice. Acta Anaesthesiol Scand. 2016;60(3):289-334. doi:10.1111/aas.12651

154. Gustafsson UO, Scott MJ, Hubner M, et al. Guidelines for perioperative care in elective colorectal surgery: Enhanced Recovery After Surgery (ERAS((R))) Society Recommendations: 2018. World J Surg. 2019;43(3):659-695. doi:10.1007/s00268-018-4844-y

155. Low DE, Allum W, De Manzoni G, et al. Guidelines for perioperative care in esophagectomy: Enhanced Recovery After Surgery (ERAS ${ }^{\circledR}$ ) Society Recommendations. World J Surg. 2019;43(2):299-330. doi:10.1007/s00268-018-4786-4

156. Nygren J, Thacker J, Carli F, et al. Guidelines for perioperative care in elective rectal/pelvic surgery: Enhanced Recovery After Surgery (ERAS ${ }^{\circledR}$ ) Society recommendations. Clin Nutr. 2012;31 (6):801-816. doi:10.1016/j.clnu.2012.08.012

157. Cerantola Y, Valerio M, Persson B, et al. Guidelines for perioperative care after radical cystectomy for bladder cancer: Enhanced Recovery After Surgery (ERAS((R))) society recommendations. Clin Nutr. 2013;32(6):879-887. doi:10.1016/j. clnu.2013.09.014
158. Nelson G, Bakkum-Gamez J, Kalogera E, et al. Guidelines for perioperative care in gynecologic/oncology: Enhanced Recovery After Surgery (ERAS) Society recommendations-2019 update. Int J Gynecol Cancer. 2019;29(4):651-668. doi:10.1136/ijgc2019-000356

159. Melloul E, Hubner M, Scott M, et al. Guidelines for perioperative care for liver surgery: Enhanced Recovery After Surgery (ERAS) Society Recommendations. World $J$ Surg. 2016;40 (10):2425-2440. doi:10.1007/s00268-016-3700-1

160. Halabi WJ, Kang CY, Nguyen VQ, et al. Epidural analgesia in laparoscopic colorectal surgery: a nationwide analysis of use and outcomes. JAMA Surg. 2014;149(2):130. doi:10.1001/ jamasurg.2013.3186
Journal of Pain Research

\section{Publish your work in this journal}

The Journal of Pain Research is an international, peer reviewed, open access, online journal that welcomes laboratory and clinical findings in the fields of pain research and the prevention and management of pain. Original research, reviews, symposium reports, hypothesis formation and commentaries are all considered for publication. The manuscript

Submit your manuscript here: https://www.dovepress.com/journal-of-pain-research-journa
Dovepress

management system is completely online and includes a very quick and fair peer-review system, which is all easy to use. Visit http:// www.dovepress.com/testimonials.php to read real quotes from published authors. 